\title{
Adipocyte JAK2 mediates growth hormone-induced hepatic insulin resistance
}

Kevin C. Corbit, ${ }^{1}$ João Paulo G. Camporez, ${ }^{2}$ Jennifer L. Tran, ${ }^{1}$ Camella G. Wilson, ${ }^{1}$ Dylan A. Lowe, ${ }^{1}$ Sarah M. Nordstrom, ${ }^{1}$ Kirthana Ganeshan, ${ }^{1}$ Rachel J. Perry, ${ }^{2}$ Gerald I. Shulman, ${ }^{2,3,4}$ Michael J. Jurczak, ${ }^{5}$ and Ethan J. Weiss ${ }^{1}$

'Cardiovascular Research Institute, UCSF, San Francisco, California, USA. ${ }^{2}$ Department of Internal Medicine, ${ }^{3}$ Cellular and Molecular Physiology, and ${ }^{4}$ Howard Hughes Medical Institute, Yale University School of Medicine, New Haven, Connecticut, USA. ${ }^{5}$ Department of Medicine, Division of Endocrinology and Metabolism, University of Pittsburgh, Pittsburgh, Pennsylvania, USA.

For nearly 100 years, growth hormone (CH) has been known to affect insulin sensitivity and risk of diabetes. However, the tissue governing the effects of $\mathrm{GH}$ signaling on insulin and glucose homeostasis remains unknown. Excess $\mathrm{CH}$ reduces fat mass and insulin sensitivity. Conversely, CH insensitivity (GHI) is associated with increased adiposity, augmented insulin sensitivity, and protection from diabetes. Here, we induce adipocyte-specific $\mathrm{GHI}$ through conditional deletion of Jak2 (JAK2A), an obligate transducer of GH signaling. Similar to whole-body GHI, JAK2A mice had increased adiposity and extreme insulin sensitivity. Loss of adipocyte Jak2 augmented hepatic insulin sensitivity and conferred resistance to diet-induced metabolic stress without overt changes in circulating fatty acids. While $\mathrm{GH}$ injections induced hepatic insulin resistance in control mice, the diabetogenic action was absent in JAK2A mice. Adipocyte GH signaling directly impinged on both adipose and hepatic insulin signal transduction. Collectively, our results show that adipose tissue governs the effects of $\mathrm{CH}$ on insulin and glucose homeostasis. Further, we show that JAK2 mediates liver insulin sensitivity via an extrahepatic, adipose tissue-dependent mechanism.

Authorship note: M.J. Jurczak and E.J. Weiss are co-senior authors.

Conflict of interest: The authors have declared that no conflict of interest exists.

Submitted: September 29, 2016 Accepted: December 19, 2016 Published: February 9, 2017

Reference information: JCI Insight. 2017;2(3):e91001. https:// doi.org/10.1172/jci.insight.91001.

\section{Introduction}

Bernardo Houssay, an Argentinian physician-scientist, demonstrated that injection of anterior pituitary extract worsens glycemic control in dogs $(1,2)$. In contrast, loss of anterior pituitary function leads to hypoglycemia and increased sensitivity to insulin (3). Similar results were observed in humans, in which hypophysectomy ameliorates not only insulin resistance (4-6) but diabetic complications as well $(7,8)$. More recently, it has been demonstrated that growth hormone $(\mathrm{GH})$ is responsible for much of the pituitaryderived diabetogenic activity (9). Both loss- and gain-of-function studies in humans and rodents support a role for GH in the biology of insulin responsiveness. Specifically, loss of GH receptor (GHR) function in humans and mice is associated with insulin sensitivity and protection against age-related diabetes $(10,11)$. Conversely, acromegalic patients with excessive GH secretion and transgenic Gh overexpressing mice have increased mortality and insulin resistance (12-14). Collectively, robust physiologic and genetic data support a prominent role for $\mathrm{GH}$ signaling in insulin/glucose homeostasis and the etiology of diabetes.

One of the major physiological functions of $\mathrm{GH}$ is controlling adipose tissue lipolysis $(15,16)$ Recent studies have demonstrated a critical role for insulin-mediated suppression of adipocyte lipolysis in the acute inhibition of hepatic gluconeogenesis through reductions in hepatic acetyl-CoA, leading to decreased pyruvate carboxylase activity and flux (17). Further, glucocorticoid-induced lipolysis (18) and macrophage-induced lipolysis associated with obesity were shown to promote increased rates of hepatic gluconeogenesis and fasting hyperglycemia by promoting increased hepatic acetyl CoA content and pyruvate carboxylase activity/flux as well as increased conversion of glycerol to glucose (17). Although the ability for GH to promote lipolysis directly is ambiguous, data supporting a causal role for lipolysis in GH-mediated insulin resistance are robust $(19,20)$. The role, if any, of lipolytic activity in GH deficiency or GH insensitivity-associated (GHI-associated) augmentation of insulin sensitivity is entirely unknown. 
The tissue(s) mediating the effects of GH signaling on insulin and glucose homeostasis has been elusive. Loss of GH signaling in liver through conditional deletion of Ghr (21), Stat5 (22), or Jak2 (23) confers lean body mass, fatty liver, and insulin resistance. In stark contrast, mice (24) and humans (10) with global disruption of GHR have increased adiposity and insulin sensitivity.

There are conflicting results regarding the effect of skeletal muscle GHI on whole-body insulin sensitivity $(25,26)$. Additionally, the effects of skeletal muscle-specific loss of GHI on insulin sensitivity do not phenocopy the effects of global GHI deficiency. Mice with $\beta$ cell-specific disruption of GHR show little effect on fasting plasma insulin levels or insulin content in the pancreas on normal chow (27). Recently, mice with fat-specific disruption of GHR were described to have increased fat mass but no change in insulin or glucose homeostasis (28). However, these mice were generated using the Fabp4:Cre, which is known to have activity outside of adipose tissue (29).

In an effort to determine the specific role of adipose tissue in the metabolic activity of $\mathrm{GH}$, we deleted Jak2 from adipocytes using Adiponectin:Cre (here termed JAK2A) (30). Similar to whole-body GHI, and as described earlier, the resulting JAK2A mice had increased adiposity. Yet, they also had improved whole-body insulin sensitivity. Interestingly, while chronic systemic GH exposure promoted hepatic insulin resistance and lipolysis in control mice, JAK2A animals were refractory to the diabetogenic action of GH. Prominent mechanisms regulating hepatic insulin sensitivity, including reductions in plasma free fatty acid concentrations and liver lipid content, failed to account for the insulin-sensitizing effects observed in JAK2A mice. Collectively, our work demonstrates that adipose tissue regulates the diabetogenic activity of $\mathrm{GH}$ and that a JAK2-dependent, adipose-derived factor mediates whole-body insulin sensitivity.

\section{Results}

Adipocyte-specific deletion of Jak2 augments adiposity and insulin responsiveness. We disrupted Jak2 specifically in adipocytes using Adiponectin:Cre on an inbred C57BL/6 background (31). All studies were performed using male mice. On normal chow, body weight between control and JAK2A cohorts did not differ (Figure 1A). However, JAK2A mice had increases in both absolute and percentage body fat (Figure 1, B and C). Both visceral epididymal and subcutaneous inguinal fat pad mass were higher in JAK2A animals (Figure 1, D and E) and were accompanied by adipocyte hypertrophy (Supplemental Figure 1, A and B; supplemental material available online with this article; http://doi.org/10.1172/jci.insight.91001DS1) without changes in immunological populations (Supplemental Figure 1, C-G) or circulating IL-6 (Supplemental Figure $1 G)$. Despite increased adiposity, fasting JAK2A mice were hypoglycemic and trended toward hypoinsulinemia (Figure 1, F and G), implying increased whole-body insulin sensitivity. Consistent with this, the JAK2A cohort was hyperresponsive to insulin during the insulin tolerance test (Figure $1 \mathrm{H})$. Thus, despite increased adiposity, JAK2A mice have augmented whole-body insulin responsiveness.

Increased hepatic insulin sensitivity and suppression of endogenous glucose production in JAK2A mice. To definitively determine tissue-specific insulin sensitivity, hyperinsulinemic-euglycemic clamps were performed. There was no difference in clamped plasma insulin levels between groups during the clamp (Supplemental Figure 2B), and plasma glucose levels were matched at approximately $120 \mathrm{mg} / \mathrm{dl}$ (Figure 2A). As compared with the control cohort, JAK2A animals required a higher glucose infusion rate (GIR) to maintain euglycemia, confirming augmented whole-body insulin sensitivity (Figure 2, B and C). While basal endogenous glucose production (EGP) was unchanged between groups (Figure 2D), clamped JAK2A mice fully suppressed EGP following insulin infusion and to a much greater extent than control animals (Figure 2, $\mathrm{E}$ and F), demonstrating improved hepatic insulin sensitivity. Whole-body glucose disposal (Figure $2 \mathrm{G}$ ) and skeletal muscle- (Figure 2H) and adipose tissue-specific (Figure 2I) glucose uptake did not differ between the cohorts. Therefore, disruption of adipocyte Jak2 confers improved whole-body insulin sensitivity almost entirely via augmented hepatic insulin sensitivity and suppression of hepatic glucose production.

Enhanced insulin-mediated suppression of lipolysis in JAK2A mice. It was recently shown that reductions in adipocyte lipolysis and fatty acids (FAs) are major regulators of insulin-mediated suppression of hepatic glucose production $(17,32)$. Since $\mathrm{GH}$ is a major in vivo regulator of lipolysis and loss of adipocyte Jak2 greatly augmented insulin-induced reductions in EGP, we examined FA levels in the clamped mice. Plasma FA concentrations did not statistically differ between the euglycemic control and JAK2A cohorts (Figure 2J). Following insulin infusion, the JAK2A cohort had lower absolute plasma FA concentrations (Figure $2 \mathrm{~K}$ ). In addition, insulin-mediated attenuation of isoproterenol-stimulated lipolysis was augmented in JAK2A adipose explants (Supplemental Figure 2H). However, no difference was appreciated between con- 
A

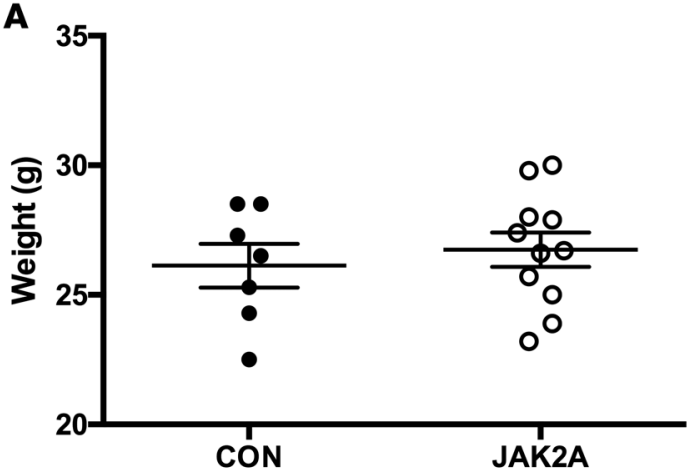

C

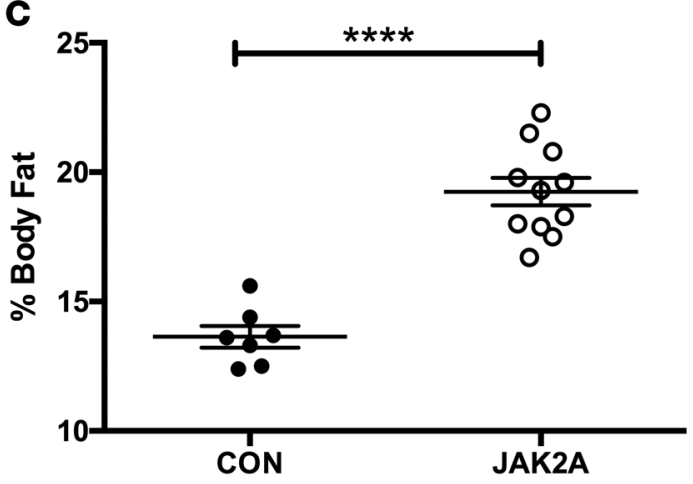

E

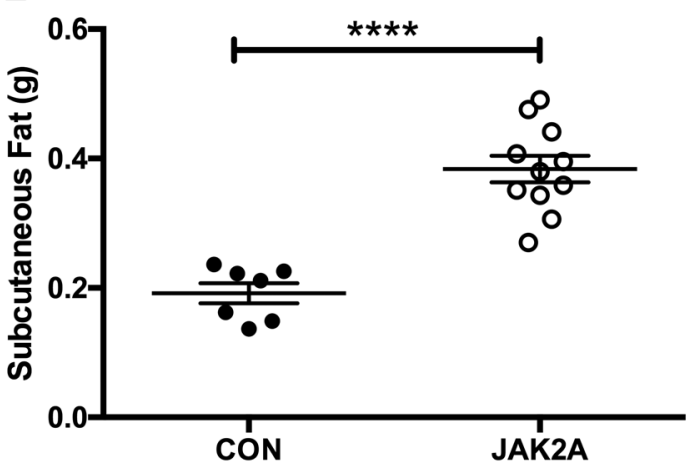

G

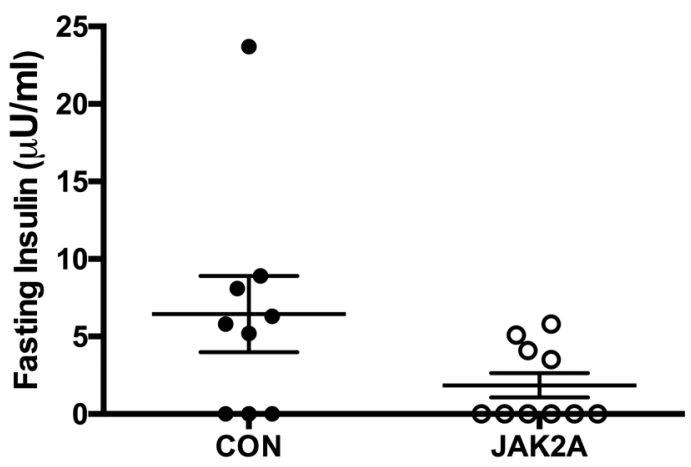

B

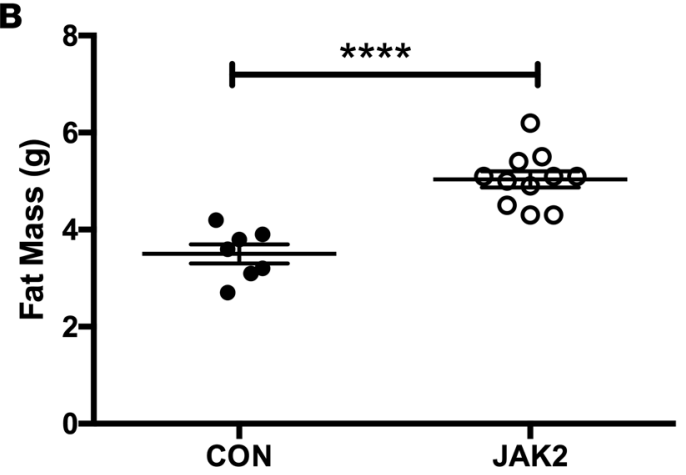

D

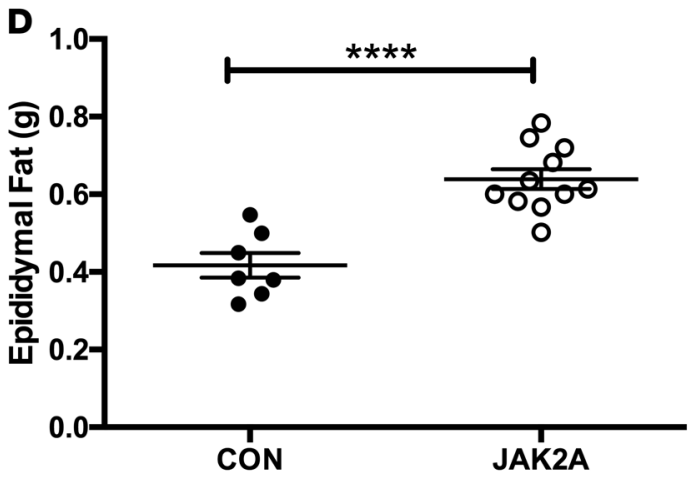

F

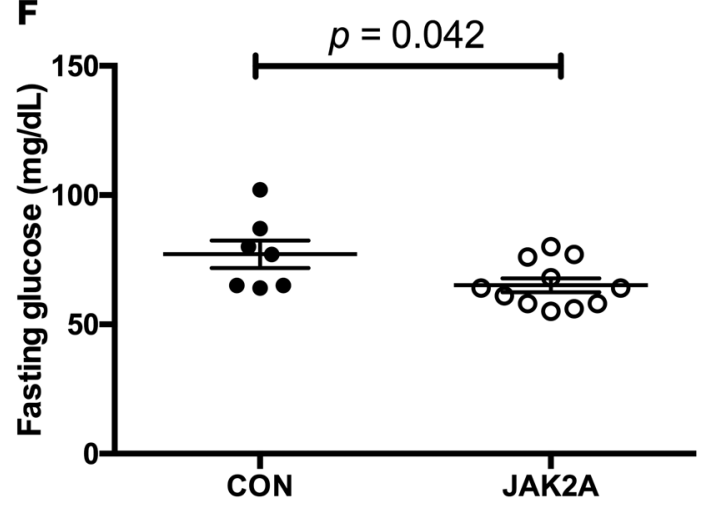

H

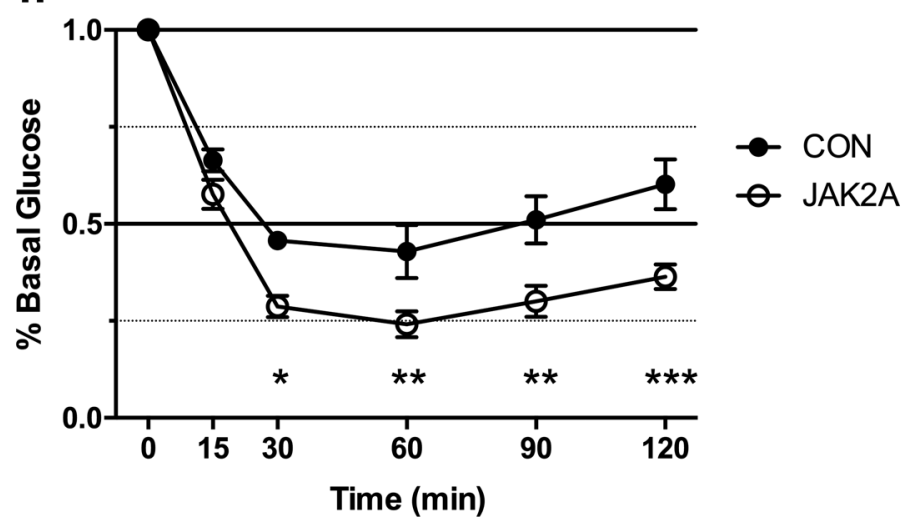

Figure 1. Loss of adipocyte Jak2 augments insulin responsiveness in chow-fed mice. (A) Total body weight and (B) fat mass in control (CON, black circles) and JAK2A mice (white circles). (C) Percentage body fat as a fraction of total body weight. (D) Total epididymal visceral and (E) inguinal subcutaneous fat. (F) Fasting blood glucose and (G) plasma insulin. (H) Insulin tolerance testing expressed as a percentage of basal (fasting) glucose in control (black circles) and JAK2A (white circles) mice. ${ }^{*} P<0.05,{ }^{* *} P<0.01,{ }^{* * *} P<0.001,{ }^{* * *} P<0.0001$ by $t$ test $(\mathbf{B}-\mathbf{F})$ and 1 -way ANOVA (H). $n=7-11$ for both cohorts. Data represent \pm SEM. 
A

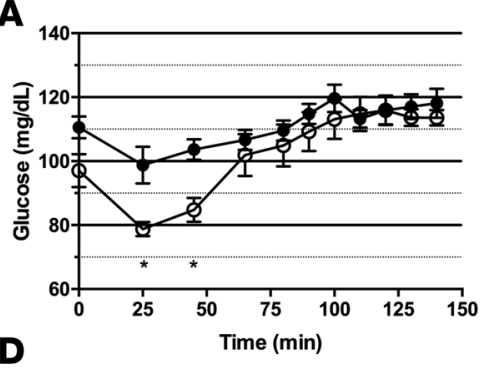

D

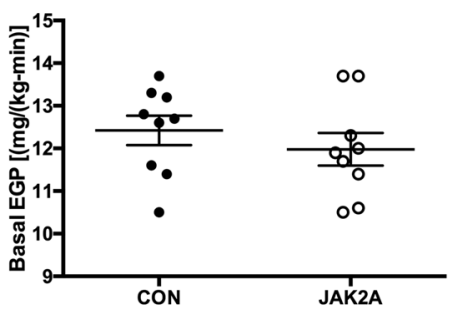

G
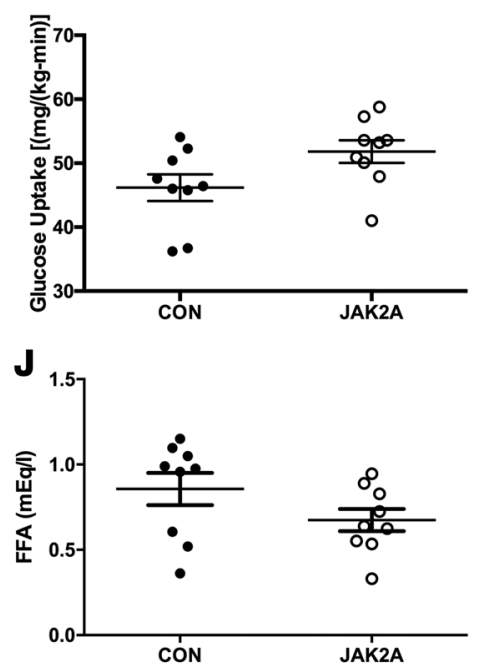

B
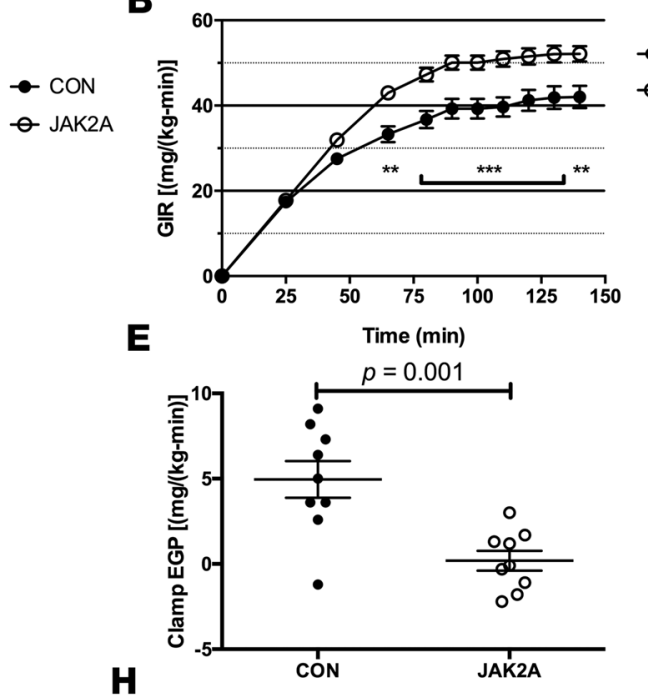

H
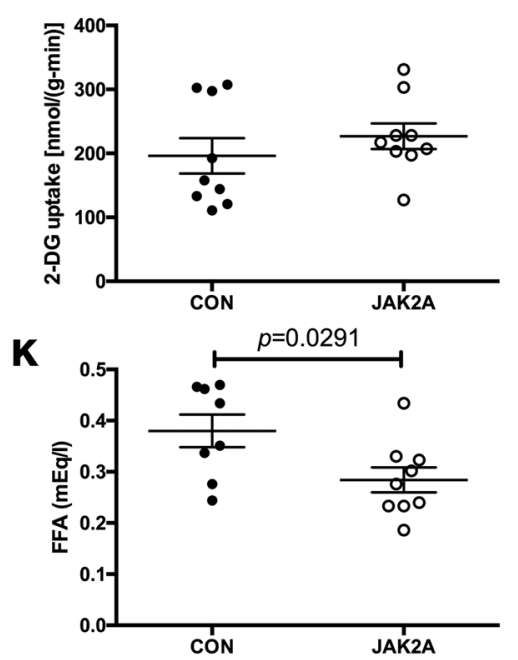
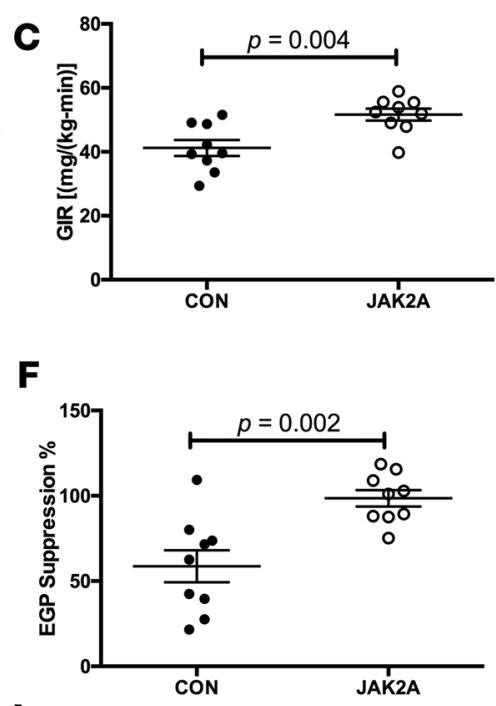

I

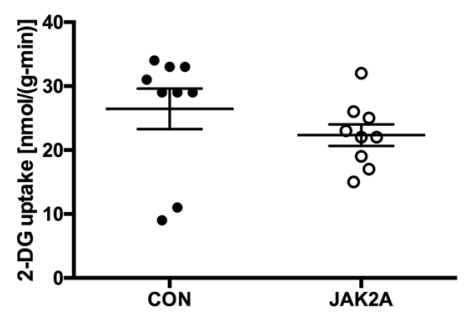

$\mathbf{L}$

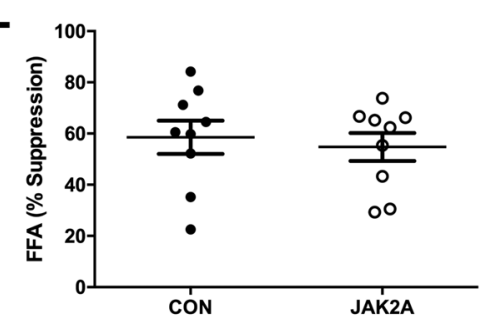

Figure 2. Adipocyte Jak2 mediates hepatic insulin sensitivity in chow-fed mice. (A) Blood glucose levels and (B) glucose infusion rate (CIR) during glucose infusion to achieve euglycemia in control (CON, black circles) and JAK2A (white circles) mice. (C) GIR at euglycemia in control and JAK2A mice. (D) Basal and (E) clamped endogenous glucose production (ECP) in control and JAK2A mice. (F) Percentage suppression of EGP following insulin infusion in control and JAK2A mice. (G) Whole-body glucose uptake in control and JAK2A mice. (H) 2-Deoxyglucose (2-DC) uptake in gastrocnemius and (I) epididymal visceral fat in control and JAK2A mice. (J) Basal and (K) clamped plasma free fatty acid (FFA) levels in control and JAK2A mice. (L) Percentage suppression of plasma FFA following insulin infusion in control and JAK2A mice. ${ }^{*} P<0.05$, ${ }^{* *} P<0.01,{ }^{* *} P<0.001$ by 1-way ANOVA. $n=9$ for both cohorts. Data represent \pm SEM.

trol and JAK2A mice when expressed as a percentage of suppression of basal FAs (Figure 2L). Thus, while reduced lipolysis may contribute to augmented hepatic insulin sensitivity in JAK2A mice, the magnitude of difference between insulin-mediated suppression of EGP and FAs (compare Figure 2E and Figure 2K) presents the possibility of potential alternative mechanisms.

$J A K 2 A$ mice are resistant to diet-induced metabolic derangement. To determine the susceptibility to metabolic stress, we next challenged mice with a high-fat diet (HFD). After 10 weeks of HFD, body weight (Figure $3 \mathrm{~A}$ ), total (Figure 3B) and percentage (Figure 3C) fat mass, and epididymal fat mass (Figure 3D) were unchanged between the control and JAK2A cohorts. The inguinal subcutaneous fat pads weighed more in JAK2A mice (Figure 3E). Both fasting blood glucose and insulin were reduced in JAK2A animals (Figure $3, \mathrm{~F}$ and $\mathrm{G}$ ). During insulin tolerance testing, the JAK2A cohort maintained remarkable insulin responsiveness, suggesting whole-body insulin sensitivity was preserved despite HFD (Figure $3 \mathrm{H}$ ).

$J A K 2 A$ mice maintain exquisite hepatic insulin sensitivity following HFD, without changes in plasma FA levels. Hyperinsulinemic-euglycemic clamp experiments showed conclusively that JAK2A mice retained exquisite 
A

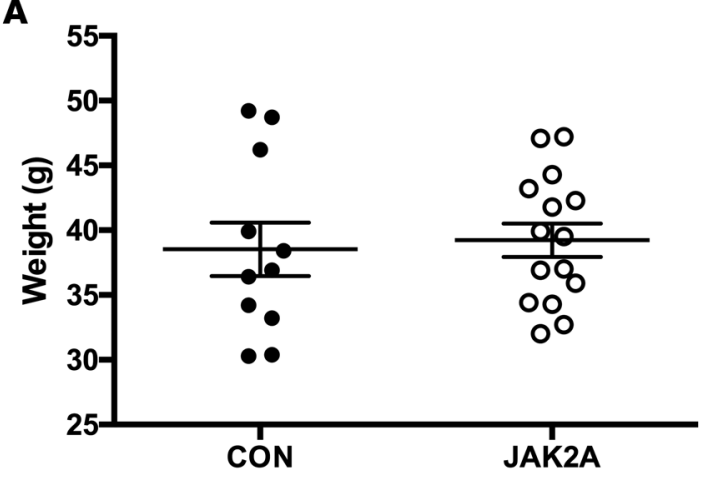

C

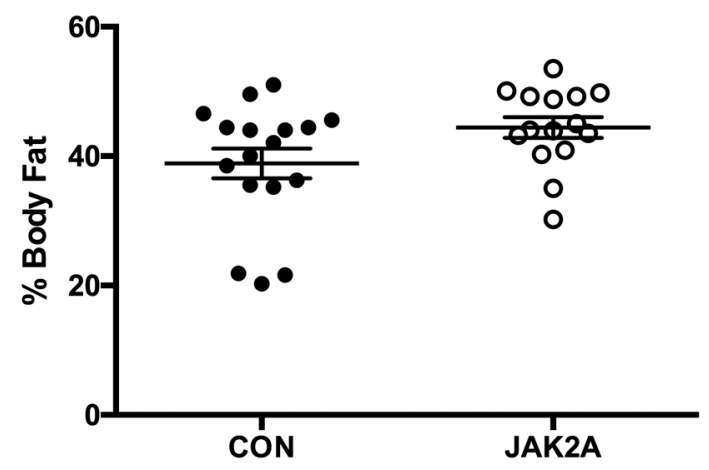

E

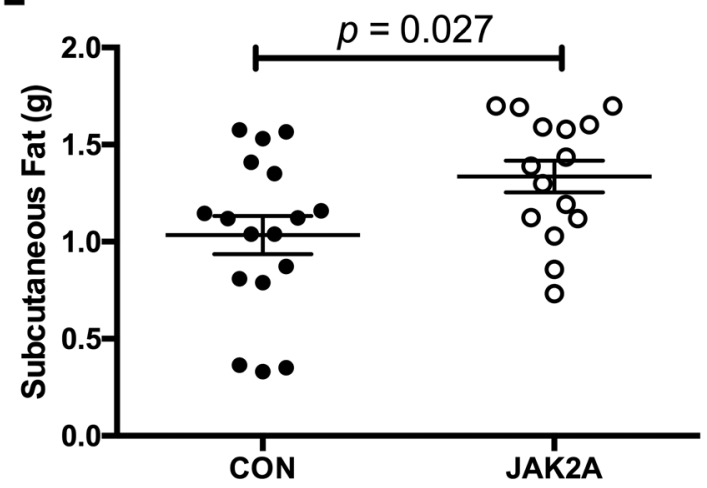

G

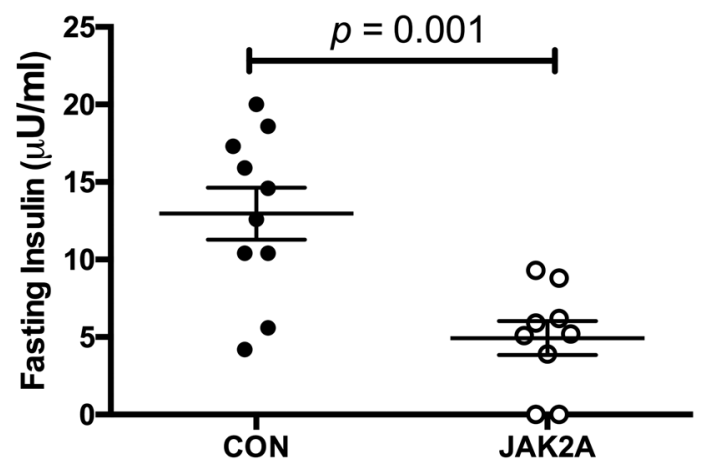

B

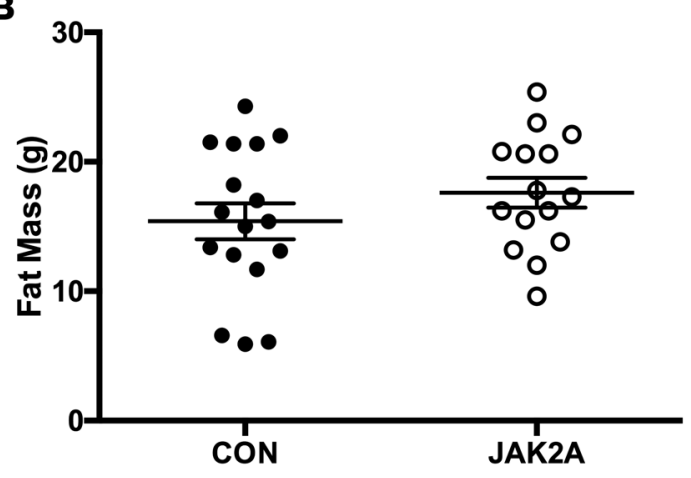

D

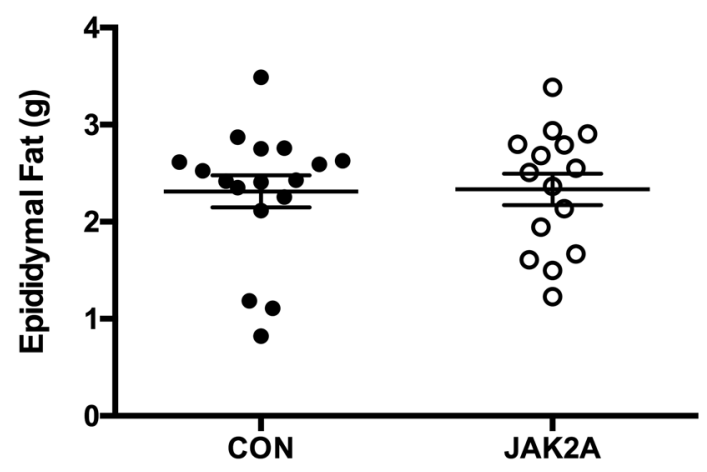

$\mathbf{F}$

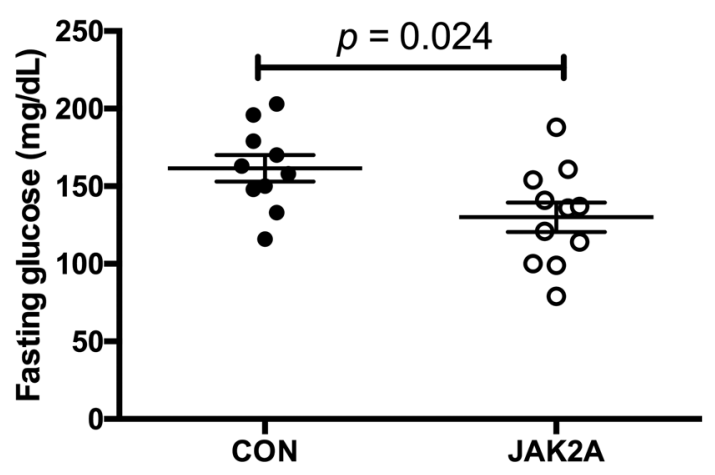

H

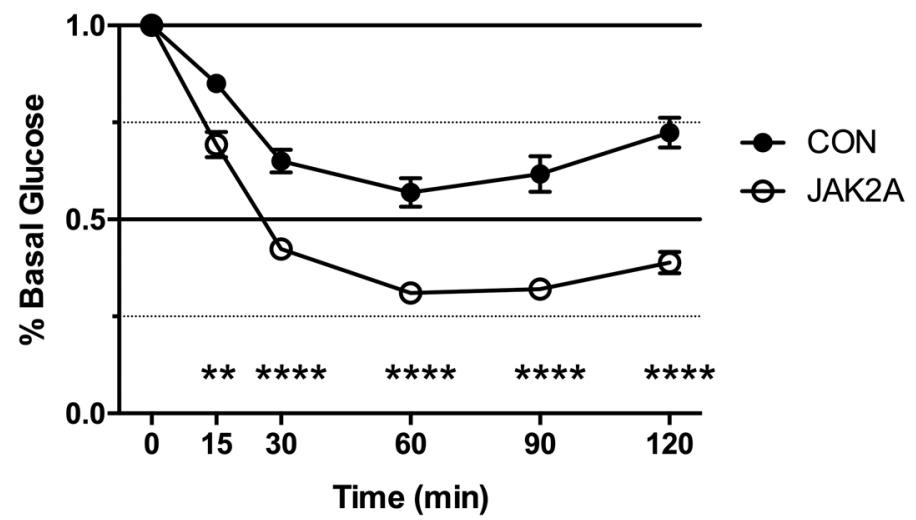

Figure 3. JAK2A mice maintain exquisite insulin responsiveness following dietary challenge. (A) Total body weight and (B) fat mass in control (CON, black circles) and JAK2A mice (white circles). (C) Percentage body fat as a fraction of total body weight. (D) Total epididymal visceral and (E) inguinal subcutaneous fat. (F) Fasting blood glucose and (G) plasma insulin. (H) Insulin tolerance testing expressed as a percentage of basal (fasting) glucose in control (black circles) and JAK2A (white circles) mice. ${ }^{* *} P<0.01,{ }^{* * * *} P<0.0001$ by 1 -way ANOVA. $n=8-16$ for both cohorts. Data represent \pm SEM. 
insulin sensitivity following HFD. Plasma insulin (Supplemental Figure 2D) and glucose levels (Figure 4A) were matched in response to a fixed and variable rate of infusion, respectively, during the clamp. At steady state, the GIR was nearly doubled in JAK2A animals (Figure 4, B and C). Similar to mice on chow, basal EGP was unchanged between the groups (Figure 4D). However, while clamped control mice demonstrated hepatic insulin resistance, EGP was completely suppressed following insulin infusion in JAK2A animals and, furthermore, appeared negative (Figure 4, E and F). Negative EGP, as measured by tracer dilution during a hyperinsulinemic-euglycemic clamp, is a well-documented phenomenon that typically occurs in extremely insulin-sensitive models with high rates of glucose turnover, likely due to variable mixing of the exogenous $3-{ }^{3} \mathrm{H}$-glucose tracer with the endogenous glucose pool (33). Variable mixing of the $3-{ }^{3} \mathrm{H}$-glucose tracer also affects measures of whole-body glucose disposal, which appeared unchanged between the two cohorts (Figure 4G). However, plasma clearance and tissue accumulation of the nonmetabolizable glucose tracer ${ }^{14} \mathrm{C}$-2-deoxyglucose (2-DG) are not affected by variable mixing and are therefore a more direct and reliable measure of glucose disposal. Tissue-specific glucose transport determined by 2-DG clearance was significantly increased in both skeletal muscle (Figure $4 \mathrm{H}$ ) and adipose tissue (Figure 4I) in JAK2A mice. These data demonstrate that, despite the technical limitations of the $3-{ }^{3} \mathrm{H}$-glucose tracer under the conditions used, both hepatic and peripheral insulin sensitivity were improved in HFD JAK2A mice. In contrast, basal (Figure 4J) and insulin-mediated suppression of plasma FAs (Figure 4, K and L) did not differ between control and JAK2A animals. Therefore, adipocyte Jak2 mediates whole-body insulin sensitivity even when challenged with HFD. Further, JAK2A mice augmented hepatic insulin sensitivity independent of statistically significant changes in FA levels. Collectively, JAK2A mice are resistant to the metabolic derangements of HFD.

Reduced hepatic triacylglycerol levels do not account for increased insulin sensitivity in chow-fed JAK2A mice. Increased tissue lipid deposition strongly correlates with insulin resistance. Therefore, we reasoned that livers of JAK2A mice would have reduced lipid burden. Surprisingly, total levels of hepatic triacylglycerol (TAG) were unaltered between control and JAK2A chow-fed cohorts (Supplemental Figure 2E). Therefore, hepatic insulin sensitivity in chow-fed JAK2A mice is not associated with reduced total liver lipid content. Following HFD, hepatic TAG content was increased in both control and JAK2A animals (Supplemental Figure 2E). Hepatic TAG levels in HFD-fed JAK2A mice were lower than those in the control cohort and hence may contribute to preserved insulin sensitivity in JAK2A animals following dietary challenge.

Acute GH treatment induces hepatic insulin resistance, which is dependent on adipocyte Jak2. Having established that insulin sensitivity is augmented in the setting of loss-of-function JAK2A mutants, we next determined the role of adipose tissue Jak2 in gain-of-function GH signaling. To this end, control and JAK2A mice were treated with vehicle or supraphysiological doses of recombinant mouse GH daily for 5 days. GH treatment induced hyperinsulinemia in control and, to a lesser extent, in JAK2A mice (Supplemental Figure 2F). Following the hyperinsulinemic clamp, plasma insulin levels were equivalent in all groups (Supplemental Figure $2 \mathrm{G}$ ). Plasma glucose levels were fixed in all cohorts at $\sim 120 \mathrm{mg} / \mathrm{dL}$ (Figure 5A). Similar to our previous chow-fed clamp study (Figure 2), vehicle-injected JAK2A mice required a higher GIR compared with the control cohort (Figure 5, B and C). Systemic GH treatment reduced GIR by approximately 35\% in control animals and by approximately 19\% in JAK2A mice (Figure 5C). Basal EGP did not differ between groups (Figure 5D). Consistent with our previous study, JAK2A vehicle-treated mice demonstrated augmented EGP suppression following insulin infusion (Figure 5F). Conversely, GH treatment significantly reduced insulin-mediated EGP suppression in control animals, confirming the diabetogenic activity of GH (Figure 5F). Remarkably, GH injections had no effect on hepatic insulin sensitivity in the JAK2A cohort (Figure 5 , $\mathrm{E}$ and F). GH treatment diminished whole-body glucose disposal (Figure $5 \mathrm{G}$ ) and skeletal muscle glucose uptake (Figure $5 \mathrm{H}$ ) in both control and JAK2A mice. No differences in adipose tissue glucose uptake were observed (Figure 5I). Thus, systemic GH exposure for only 5 days induces hepatic insulin resistance in an adipocyte Jak2-dependent manner.

GH promotes adipocyte lipolysis indirectly via JAK2-dependent inhibition of insulin action. In hyperinsulinemic-euglycemic clamped mice, circulating basal FA levels were unchanged in GH-injected animals (Figure 5J). Following insulin infusion, GH-injected control animals failed to suppress plasma FAs to the levels of vehicle-treated mice, revealing that GH promoted lipolysis indirectly via inhibitory effects on insulin activity (Figure $5 \mathrm{~K}$ ). The ability of $\mathrm{GH}$ to antagonize reductions in circulating FAs was absent in JAK2A mice (Figure 5, K and L), demonstrating that adipocyte Jak2 transduces the GH signal to interfere with insulin-mediated suppression of lipolysis. This correlated with retention of hepatic insulin sensitivity 
A

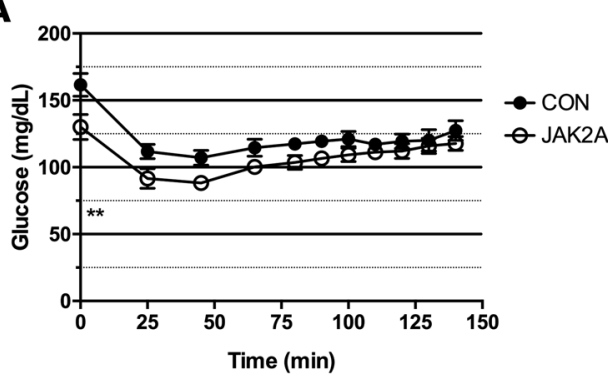

D

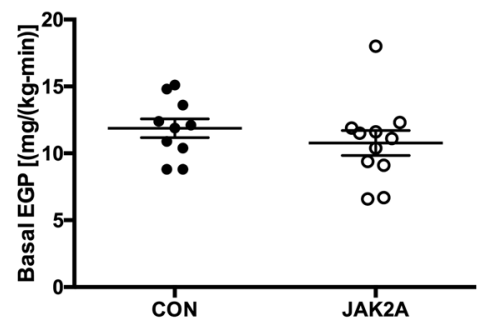

G

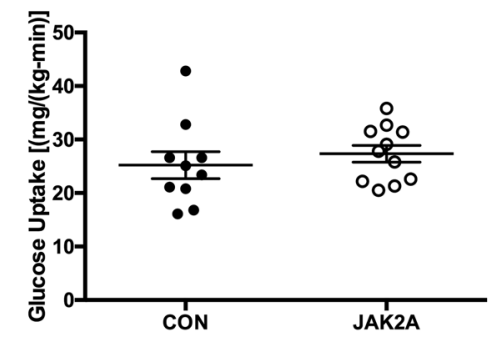

J

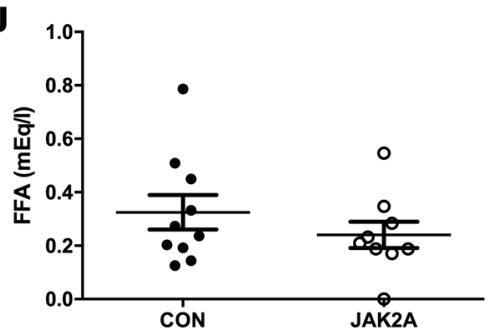

B

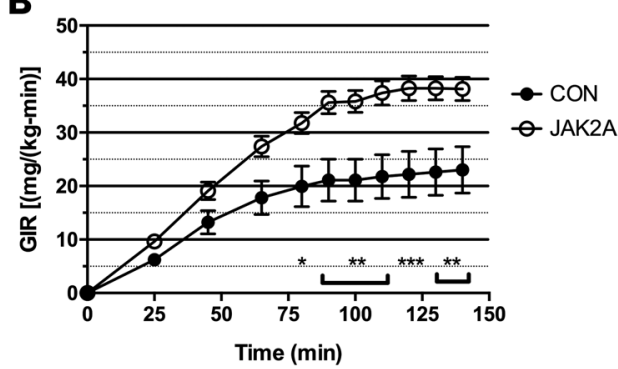

E

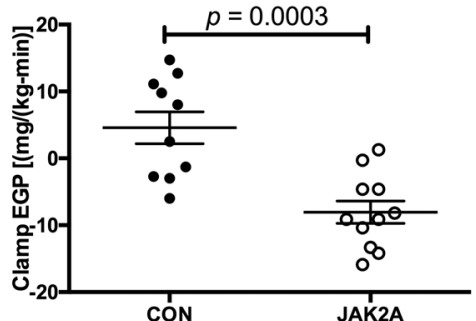

H
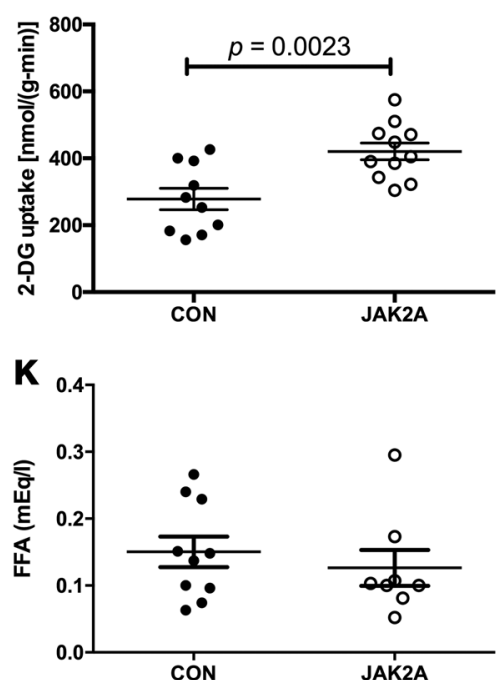

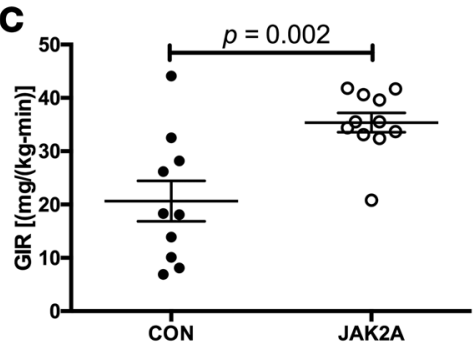

F

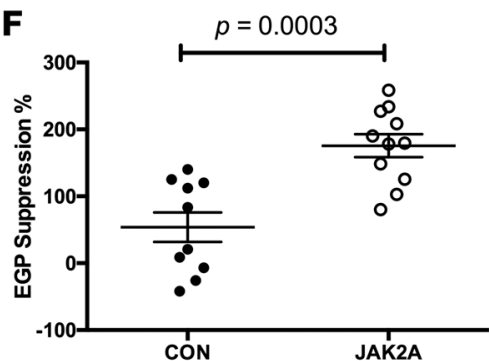

I
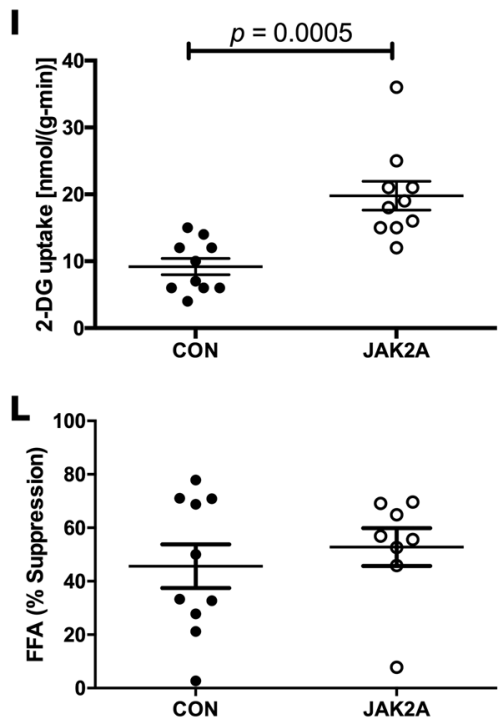

Figure 4. Loss of adipocyte Jak2 imparts hepatic and whole-body insulin sensitivity in high-fat diet-fed mice. (A) Plasma glucose levels and (B) glucose infusion rate (GIR) during glucose infusion to achieve euglycemia in control (CON, black circles) and JAK2A (white circles) mice. (C) GIR at euglycemia in control and JAK2A mice. (D) Basal and (E) clamped endogenous glucose production (EGP) in control and JAK2A mice. (F) Percentage suppression of EGP following insulin infusion in control and JAK2A mice. (G) Whole-body glucose uptake in control and JAK2A mice. (H) 2-Deoxyglucose (2-DG) uptake in gastrocnemius and (I) epididymal visceral fat in control and JAK2A mice. (J) Basal and (K) clamped plasma fatty acid (FFA) levels in control and JAK2A mice. (L) Percentage suppression of plasma FFA following insulin infusion in control and JAK2A mice. ${ }^{*} P<0.05,{ }^{* *} P<0.01,{ }^{* * *} P<0.001$ by 1-way ANOVA. $n=8-11$ for both cohorts. Data represent \pm SEM.

(Figure 5E). Collectively, we conclude that adipose tissue mediates GH-dependent antagonism of insulin's activity in both hepatocytes and adipocytes.

Similar to our earlier clamp experiment (Figure 2), neither basal (Figure 5J) nor percentage of suppression of circulating plasma free FAs (Figure 5L) differed between vehicle-treated control and JAK2A animals. Again, the lack of a demonstrable effect on lipolysis occurred concurrent with augmented hepatic insulin sensitivity (Figure 5E). A nearly identical pattern was observed for palmitate turnover (Supplemental Figure 2, I-K). Therefore, hepatic insulin resistance in GH-treated control animals directly correlates with adipocyte Jak2-dependent lipolysis. Further, the augmented hepatic insulin sensitivity of JAK2A mice may be mediated by a mechanism(s) other than or in addition to inhibition of lipolysis.

GH treatment impairs adipocyte insulin responsiveness. Since GH attenuated insulin-mediated suppression of lipolysis (Figure $5 \mathrm{~K}$ ), we determined the ability of insulin to induce signal transduction in adipose tissue 
A

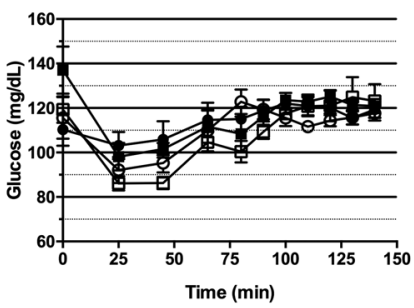

D

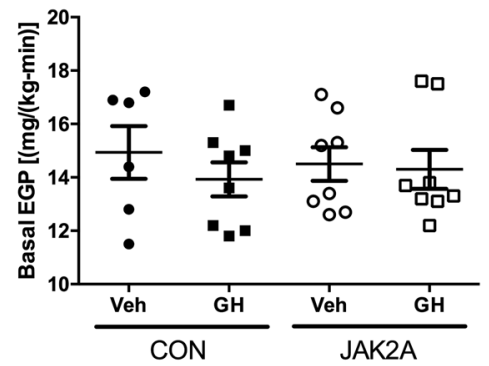

G

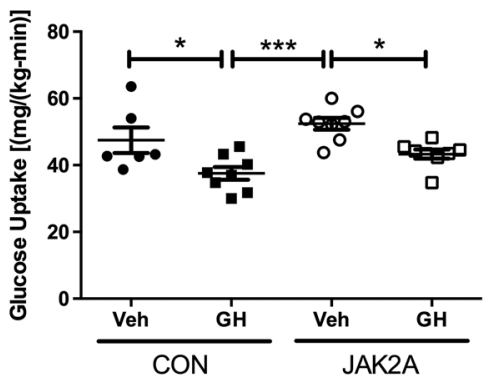

J

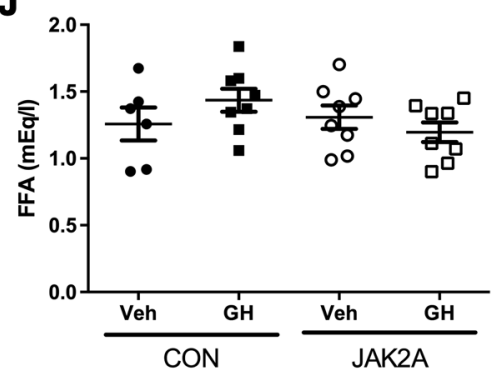

B

$\rightarrow \mathrm{CON}+\mathrm{Veh}$

$-\mathrm{CON}+\mathrm{GH}$

$\because \mathrm{JAK} 2 \mathrm{~A}+\mathrm{Veh}$

\& JAK2A+GH
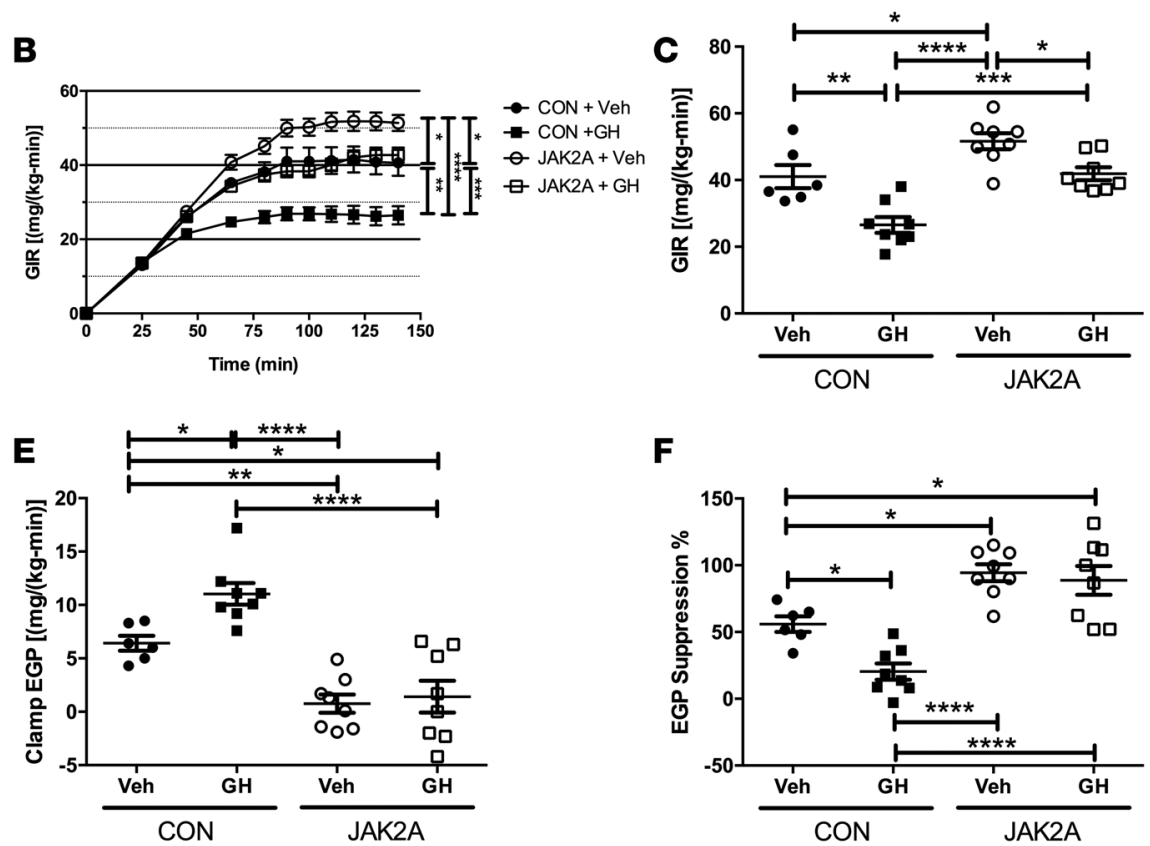

H
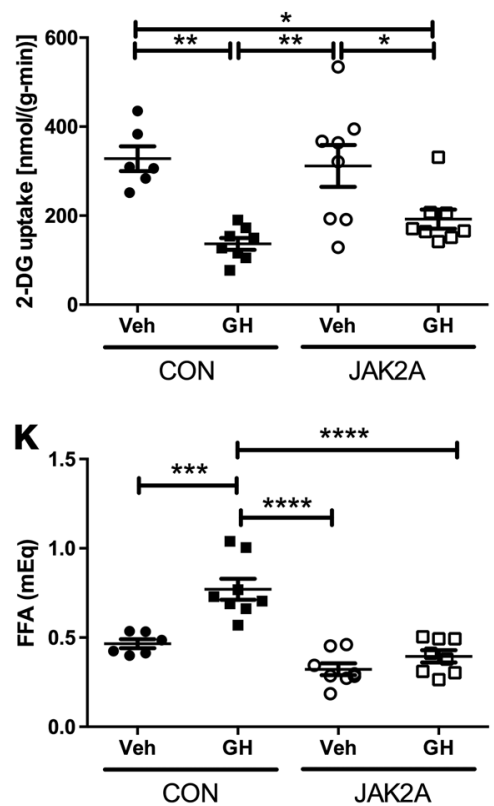

$\mathbf{F}$

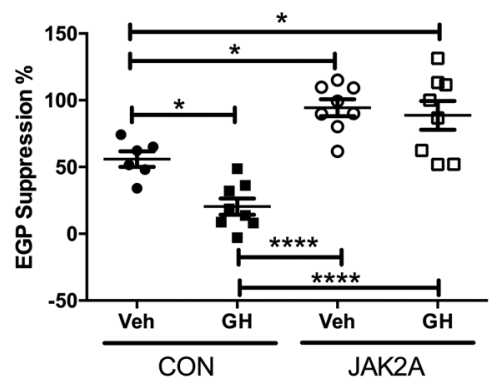

】
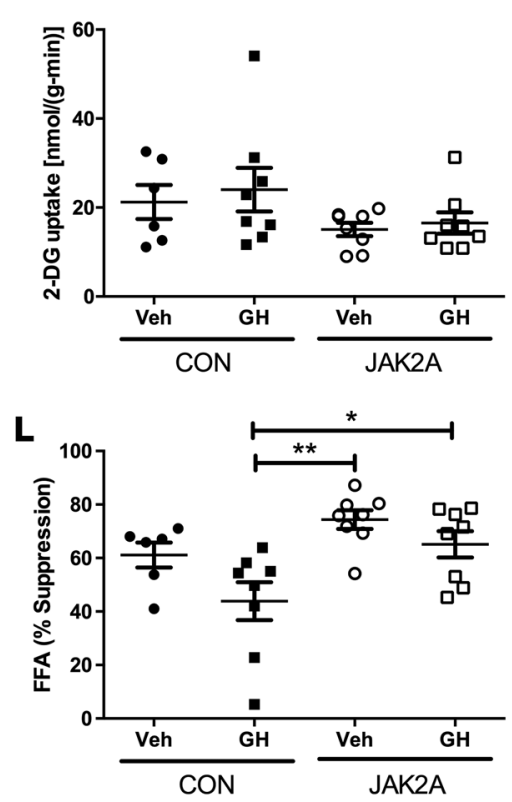

Figure 5. Adipocyte Jak2 is required for growth hormone-induced hepatic insulin resistance and lipolysis. (A) Plasma glucose levels and (B) glucose infusion rate (GIR) during glucose infusion to achieve euglycemia in vehicle-injected (Veh-injected) control (CON, black circles) and JAK2A (white circles) mice and growth hormone-injected (CH-injected) control (black squares) and JAK2A (white squares) cohorts. (C) GIR at euglycemia in vehicle- and $\mathrm{CH}$-injected control and JAK2A mice. (D) Basal and (E) clamped endogenous glucose production (EGP) in vehicle- and GH-injected control and JAK2A mice. (F) Percentage suppression of EGP following insulin infusion in vehicle- and GH-injected control and JAK2A mice. (G) Whole-body glucose uptake in vehicle- and GHinjected control and JAK2A mice. (H) 2-Deoxyglucose (2-DG) uptake in gastrocnemius and (I) epididymal visceral fat in vehicle- and GH-injected control and JAK2A mice. (J) Basal and (K) clamped plasma free fatty acid (FFA) levels in control and JAK2A mice. (L) Percentage suppression of plasma FFA following insulin infusion in control and JAK2A mice. ${ }^{*} P<0.05,{ }^{* *} P<0.01,{ }^{* * *} P<0.001,{ }^{* * *} P<0.0001$ by 2-way ANOVA (A and B) or 1-way ANOVA (C-L). $n=6-8$ for both cohorts. Data represent \pm SEM.

from GH-treated mice. Intraperitoneal injection of insulin induced robust insulin receptor autophosphorylation in control inguinal adipose tissue following a 10-minute exposure (Supplemental Figure 3, A and B. For full, uncut blots see online Supplemental Material). Daily GH injections for 7 days potently attenuated insulin receptor autophosphorylation in control but not JAK2A mice. Similarly, GH inhibited insulininduced AKT phosphorylation (pAKT) in a JAK2-dependent manner (Supplemental Figure 3, C and D). 
A

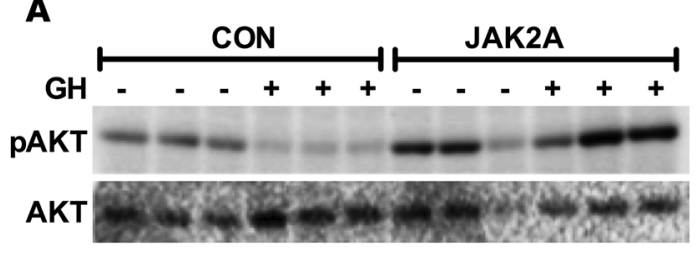

B

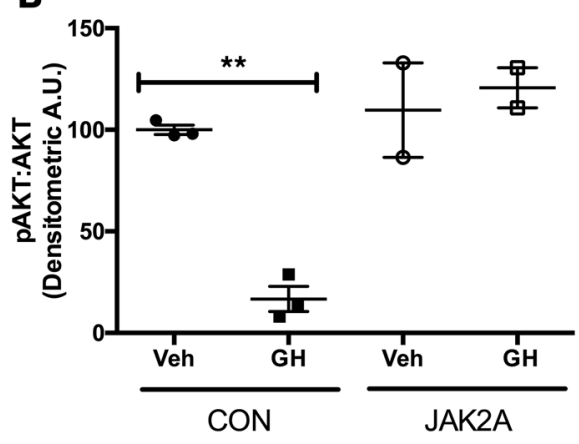

Finally, and consistent with a previous report (34), Pik3r1 $(\mathrm{p} 85 \alpha)$ levels were reduced in JAK2A inguinal adipose tissue.

Adipocyte Jak2 governs hepatic insulin responsiveness. Given that neither liver lipid content nor lipolysis strongly correlated with hepatic insulin sensitivity in mice lacking adipocyte Jak2, we measured hepatic insulin signaling in control and JAK2A cohorts. To this end, we continually exposed mice to recombinant $\mathrm{GH}$ for 28 days via mini-osmotic pumps. Subsequently, hepatic insulin responsiveness was assessed via levels of pAKT following injec-

Figure 6. Adipocyte Jak2 mediates insulin-induced hepatic AKT activation. (A) Western blot of insulin-stimulated liver lysates with antibodies against phosphorylated AKT (pAKT) and total AKT (AKT) in control (CON) and JAK2A mice following continuous delivery of vehicle (-) or recombinant growth hormone $(\mathrm{GH},+)$ for 28 days. (B) Densitometric arbitrary units ratio of PAKT/AKT in control and JAK2A mice treated (GH) or not (Veh) with GH. ${ }^{*} P<0.01$ by 1 -way ANOVA. Data represent \pm SEM.

tions into the inferior vena cava. Vehicle-infused control animals responded robustly to inferior vena cava insulin (Figure 6). Conversely, chronic GH exposure strongly abrogated insulin-induced hepatic pAKT, consistent with the diabetogenic action of GH observed during the clamp studies (Figure 5) and in previous work (35). However, GH treatment did not impair insulin-induced pAKT in JAK2A livers, demonstrating that adipocyte JAK2 mediates a GH-induced decrease in hepatic insulin responsiveness.

\section{Discussion}

Houssay and colleagues first described their landmark studies on extreme insulin sensitivity in hypophysectomized dogs nearly 100 years ago (1). In 1987, Mayer Davidson lamented that "the mechanism of GH effects on carbohydrate and lipid metabolism is far from clear." Davidson further noted that "Several studies suggest that the insulin antagonistic effects of GH may be secondary to the increased lipolysis via the glucose-FA cycle. It is disappointing to note that this was the conclusion of the last general review of this area more than 20 years ago, and we have made little progress in substantiating or refuting this hypothesis" (36). Now, almost 30 years after this review, there is still no clear understanding of the cellular or tissuelevel basis underlying the effects of $\mathrm{GH}$ on insulin and glucose homeostasis.

Global GHI, in both the physiologic and genetic context, confers insulin sensitivity throughout life. Conversely, acromegalic patients with excessive GH secretion are prone to insulin resistance, risk of diabetes, and increased mortality. In fact, it has been proposed that GH hypersecretion may be the cause as much as the consequence of poor diabetic control (37). These effects have been well documented in dogs, mice, and teleosts (38), demonstrating robust evolutionary conservation. However, the vast array of lossof-function studies describing inactivation of GHR, JAK2, or STAT5 in metabolic tissues, including liver, skeletal muscle, pancreatic $\beta$ cell, and even adipose tissue, have yielded complex and difficult to interpret results and failed to answer the key question of where GH signaling (at the cell or tissue level) mediates its effects on whole-body insulin and glucose metabolism. Here, we show conclusively that abrogation of GH signaling in adipocytes augments whole-body and hepatic insulin sensitivity, protects from HFD-induced whole-body and hepatic insulin resistance, and prevents GH-mediated hepatic insulin resistance.

Our work relies on JAK2 as a signaling intermediate to infer $\mathrm{GH}$ action. While there is clear evidence that GH signaling is entirely dependent on JAK2 in fat and other tissues, it is possible or even likely that JAK2 mediates signals downstream of other cytokine signaling receptors in fat. Conditional deletion of Ghr with AP2:Cre results in obesity with no improvements in glucose homeostasis (28). Removal of Jak2 from adipose using the same Cre transgene was reported to also induce adiposity with age-related insulin resistance (39). This is in contrast to our JAK2A mice that, while obese, are exquisitely insulin sensitive, even when challenged with HFD or supraphysiologic amounts of GH. Our work here and previously (30) utilized Adiponectin:Cre, which has been shown to be considerably more adipocyte specific (40). The AP2:Cre line induces recombinase activity in the peripheral and central nervous systems as well as adrenal medulla (41). Therefore, loss of either Ghr or Jak2 in these populations may mediate the published 
phenotypes using the AP2:Cre line $(28,39)$. Thus, in the absence of an Adiponectin:Cre-driven Ghr deletion phenotype, it is not yet possible to conclude if the insulin sensitivity conferred by lack of adipose JAK2 is entirely due to interruption of GH signaling. However, we do definitively show that adipocyte JAK2 is required for $\mathrm{GH}$ to induce adipose tissue lipolysis and hepatic insulin resistance.

Insulin resistance strongly correlates with hepatic steatosis. Mechanistically, it has been shown that the subcellular localization of diacylglycerols (DAG) and not absolute levels of liver lipid mediate hepatic insulin resistance. Specifically, DAG and $\mathrm{PKC} \varepsilon$ are membrane associated in insulin-resistant rats but lipid droplet bound in the insulin-sensitive state, preventing PKCE translocation and activation at the plasma membrane where PKC $\varepsilon$ inhibits insulin receptor kinase activity through phosphorylation of threonine 1160 (42). These findings are germane, as, in some cases, liver lipid and hepatic insulin resistance do not correlate, such as CGI-58 ASO treatment (43). For instance, we recently published work demonstrating that resolution of hepatic steatosis in hepatocyte-specific Jak2 knockout mice (JAK2L) via concomitant deletion of $C d 36$ is not sufficient to reverse the insulin resistance observed in JAK2L animals (44). Others have shown discordance between insulin resistance and tissue lipid deposition, such as in Chanarin-Dorfman syndrome and genetic forms of hepatic steatosis $(45,46)$.

Further, insulin resistance and adiposity fail to correlate in cases of Cowden and Laron syndromes $(47,48)$. In fact, one of the natural consequences of augmented adipose tissue insulin sensitivity is reduced lipolysis, and hence increased adiposity, as is experienced by patients taking insulin-sensitizing agents, such as thiazolidinedione (49). Here, we report that chow-fed JAK2A mice have increased adiposity but fail to demonstrate statistical differences in either basal or percentage suppression of lipolysis following insulin infusion.

The physiological consequences of adipose tissue insulin sensitivity are glucose uptake and suppression of lipolysis. The former occurs via Akt-regulated GLUT4 transport (50). However, exactly how insulin suppresses adipose tissue lipolysis is unknown. The major facilitator of insulin-mediated inhibition of lipolysis appears to be PDE3B (51). Surprisingly, this has been reported to occur in an Akt-independent manner (52). While GH potently attenuated insulin-induced phosphorylation of Akt (Supplemental Figure 3, C and D), no effects on adipose tissue glucose uptake were observed (Figure 5L). Therefore, GH seems to selectively affect the antilipolytic arm of adipose tissue insulin action. We were unable to detect adipose tissue PDE3B using commercially available antibodies, but a robust inquiry into the potential role of PDE3B in GH-mediated inhibition of insulin-induced suppression of lipolysis is warranted.

In 1963, Philip Randle put forth the notion that FAs may themselves induce insulin resistance (53). Indeed, increasing levels of circulating FAs highly correlate with insulin resistance (54). Further, clinical trials testing agents that reduce FAs have shown increased insulin sensitivity outcomes (55-58). One of the many actions of insulin is to inhibit adipose tissue lipolysis and hence FA release into the circulation. $\mathrm{GH}$ has also been proposed to be a major regulator of adipose tissue lipolysis (15). Indeed, acromegalic patients have enhanced lipolysis and increased adipose expression of genes that regulate lipolysis (59). Two independent trials reported that administration of the antilipolytic drug acipimox increases insulin sensitivity in GH-treated patients $(19,20)$. Collectively, these data support a predominant role for lipolysis in GH-mediated insulin resistance. Our work here supports these findings. We showed that GH-mediated lipolysis correlates with hepatic insulin resistance and that GH promoted adipose tissue lipolysis through JAK2, but indirectly via perturbation of insulin action. Therefore, the predominant diabetogenic mechanism of GH is likely due to increased adipose tissue lipolysis, promoting hepatic insulin resistance.

However, it is unknown if abrogated adipose tissue lipolysis mediates the enhancement of insulin sensitivity observed under loss-of-function conditions, such as in Laron syndrome and other forms of congenital GHI. As opposed to systemic GH treatment, our results do not support a role for modulation of lipolysis in JAK2A-associated insulin sensitivity. Specifically, we did not observe differences in circulating FAs under clamped conditions between HFD-fed control and JAK2A mice, despite augmented hepatic insulin sensitivity in the latter. This is consistent with clinical results reporting that inhibition of GH signaling in type 1 diabetics improves hepatic insulin sensitivity without a clear effect on lipolysis (60). While the results from gain- and loss-of-function GH conditions appear disparate, the effects of GH on lipolysis may be determined by the nutritional state of the organism (61). Here, we present the possibility that the acromegalic and GHI states may mediate insulin sensitivity by different mechanisms. Alternatively, adipocyte JAK2 may antagonize insulin sensitivity by additional mechanisms independent of $\mathrm{GH}$ signaling. 
Recently, three groups reported that insulin-induced reductions in hepatic glucose production can occur independently of liver insulin signaling $(17,32,62)$. This surprising finding supports older literature showing that insulin inhibits hepatic glucose output indirectly via effects on adipose tissue (63-66) and suggests that extrahepatic tissue(s) receives insulin signals to mediate hepatic insulin sensitivity. In support of this, selective enhancement of adipocyte insulin sensitivity imparts whole-body glucose homeostasis (67). Further, transplanting insulin-sensitive adipose tissue into insulin-resistant animals restores insulin responsiveness (68-70). Finally, overt lack of adipose tissue function is sufficient to induce insulin resistance (71). Therefore, adipose tissue may be the dominant regulator of whole-body insulin sensitivity.

Exactly how adipose tissue mediates hepatic insulin sensitivity is unknown, but recent mechanisms have been proposed that include lipolysis $(31,62)$. We did not observe consistent differences in adipose tissue lipolysis or liver lipid content in chow-fed, HFD-fed, or GH-treated insulin-sensitized JAK2A mice. Further, we have not measured consistent or significant changes in classic insulin-sensitizing factors, such as adiponectin and leptin (30). Therefore, adipocyte JAK2 may mediate insulin sensitivity by a novel mechanism. Previously, it was reported the GH mediates cellular insulin resistance at the level of PI 3-kinase by altering subcellular redistribution of AKT (72). We found that GH treatment attenuated insulin-induced pAKT in inguinal adipose tissue, but the molecular mechanism remains unknown.

$\mathrm{GH}$ has been reported to regulate p85 $\alpha$ expression and PI 3-kinase activity in general (34). Consistently, we observed a reduction in Pik3r1 levels in JAK2A adipose tissue (Supplemental Figure 3E), but we are unable to comment on PI 3-kinase activity. When mutated in humans with Cowden syndrome, the PI 3-kinase pathway effector PTEN promotes adiposity coupled to augmented insulin sensitivity (47).

Here, we report that loss of adipocyte Jak2 is sufficient to impart whole-body insulin sensitivity independent of adiposity and liver lipid content, suggesting the presence of a paracrine regulator of GH diabetogenic activity and highlighting cross talk between adipose and liver. Our results show that acromegaly-associated hepatic insulin resistance is a result of attenuated insulin-mediated adipose tissue lipolysis. Finally, we provide evidence to support alternative mechanisms regulating gain- and loss-of-function GH signaling-mediated effects on insulin responsiveness. Isolation of the JAK2-dependent, adipocyte-derived factor(s) mediating whole-body insulin sensitivity may someday lead to new antidiabetic therapeutics.

\section{Methods}

Additional details can be found in the Supplemental Methods.

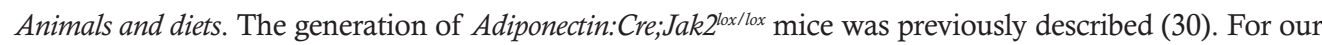
studies reported here, Jak2 $2^{\text {tox } / l o x}$ mice (73) were used as controls and backcrossed onto the C57BL/6 background for at least 9 generations. Jak2 $2^{\text {lox } / l o x}$ mice were a gift from Kay-Uwe Wagner (University of Nebraska, Lincoln, Nebraska, USA). For chow-fed studies, mice received PicoLab Mouse Diet 20 (Lab Diet 5058; percentage calories provided by protein, $23 \%$; fat, $22 \%$; and carbohydrate, $55 \%$ ), and for HFD studies, mice were fed Research Diets D12492 (percentage calories provided by protein, 20\%; fat, 60\%; and carbohydrate, 20\%).

Dietary studies. Six-week-old control and JAK2A mice were fed HFD or maintained on chow for 10 weeks. Total fat mass was determined by Dual-energy X-ray absorptiometry. Blood glucose and serum insulin levels were determined by glucometer readings (Bayer Contour) and ELISA (Alpco), respectively, following an overnight (16 hours) fast. For insulin tolerance testing, mice were fasted for 4 hours (09:0013:00) followed by intraperitoneal injection of $2 \mathrm{U} / \mathrm{kg}$ insulin (Novolin Novo Nordisk). Blood glucose levels were determined by tail prick using a hand-held glucometer at the times indicated in Figures $1 \mathrm{H}$ and $3 \mathrm{H}$.

Hyperinsulinemic-euglycemic clamp studies. Clamp studies were performed according to recent recommendations of the NIH-funded Mouse Metabolic Phenotyping Consortium and as previously described $(74,75)$. Briefly, mice recovered for 1 week after receiving surgery to implant an indwelling jugular vein catheter prior to clamp studies. Mice were fasted overnight and received a basal infusion of $3-{ }^{3} \mathrm{H}$-glucose and $\mathrm{U}_{-}{ }^{13} \mathrm{C}$-palmitate conjugated to BSA to determine fasting glucose and palmitate turnover. A primed/ continuous infusion of insulin, $3-{ }^{3} \mathrm{H}$-glucose, and $\mathrm{U}-{ }^{13} \mathrm{C}$-palmitate was administered alongside a variable infusion of $20 \%$ dextrose to maintain euglycemia during the hyperinsulinemic portion of the study. A 10 $\mu \mathrm{Ci}$ bolus injection of 2-DG was given at 90 minutes to determine tissue-specific glucose uptake, which was calculated from the area under the curve of 2-DG detected in plasma and the 2-DG-6-phosphate content of tissue. Blood was collected by tail massage at set intervals, and glucose levels were measured by a glucose oxidase method. Insulin infusion rates were as follows: chow, $2.5 \mathrm{mU} / \mathrm{kg} / \mathrm{min}$; HFD, $4.0 \mathrm{mU} /$ $\mathrm{kg} / \mathrm{min} ; \mathrm{GH}$, and $2.5 \mathrm{mU} / \mathrm{kg} / \mathrm{min}$. Glucose and palmitate turnover were determined as the ratios of the 
$3-{ }^{3} \mathrm{H}$-glucose and $\mathrm{U}-{ }^{13} \mathrm{C}$-palmitate infusion rates to the specific activity or plasma enrichment corrected to the contribution of the infusion rate for plasma glucose and palmitate, respectively, during the last $40 \mathrm{~min}$ utes of the hyperinsulinemic infusion. Calculation of endogenous glucose production and tissue-specific glucose uptake were described previously (74). For chow studies, mice were approximately 16 weeks of age, and HFD study mice were age-matched to chow studies and fed HFD for 4 weeks prior to clamps. For $\mathrm{GH}$ treatment, mice received daily vehicle (0.03 $\left.\mathrm{M} \mathrm{NaHCO}_{3}, 0.15 \mathrm{NaCl}, \mathrm{pH} 9.5\right)$ or $5 \mathrm{mg} / \mathrm{kg}$ recombinant mouse GH (A.F. Parlow, National Hormone and Peptide Program, UCLA, Torrance, California, USA) by subcutaneous injection for 5 days prior to clamp.

Mini-osmotic pump studies. Control and JAK2A mice were implanted with 28-day Alzet mini-osmotic pumps (Durect Corporation) to deliver recombinant mouse $\mathrm{GH}$ at a dose of $5 \mathrm{mg} / \mathrm{kg} / \mathrm{d}$ in GH buffer. At the end of 28 days, mice were fasted overnight (16 hours) followed by injection with $0.01 \mathrm{U}$ insulin via the inferior vena cava. After 5 minutes, the liver was removed and immediately snap frozen in liquid nitrogen. Liver tissue was prepared for gel electrophoresis as previously described (44). For detection of pAkt and total Akt, liver was homogenized in RIPA buffer (50 mM Tris, $150 \mathrm{mM} \mathrm{NaCl}, 1 \%$ Triton X-100, $1 \%$ deoxycholate, $0.1 \%$ SDS, 1 mM EDTA, $\mathrm{pH}$ 7.4) supplemented with protease and phosphatase inhibitors (Thermo Fisher Scientific). After incubating on ice for 20 minutes, the homogenate was centrifuged for 20 minutes at $15,000 \mathrm{RCF}$ at $4^{\circ} \mathrm{C}$. The protein concentration of the supernatant was determined using BCA assay (Pierce) and $20 \mu \mathrm{g}$ of protein used for gel electrophoresis. Antibodies used were anti-phosphoS473-Akt (Cell Signaling Technologies 4060) and total Akt (Cell Signaling Technologies 9272) at a dilution of 1:2,000 followed by anti-rabbit secondary at a dilution of 1:10,000. Images were collected using Chemidoc Imager (Bio-Rad).

Statistics. All statistical tests and figures were done using GraphPad Prism v6.0. For all 2 tailed $t$ tests, the $P$ value was considered significant if less than 0.05 .

Study approval. All animal studies were approved by IACUC at the UCSF, the University of Pittsburgh, and Yale University.

\section{Author contributions}

JLT performed experiments for Figures 1 and 3 and the real-time qPCR. JPGC and RJP executed experiments for Figures 2, 4, and 5. CGW carried out experiments for Figure 6 and immune cell FACS analyses. DL performed GH and insulin injections followed by adipose tissue Western blots. SN collected tissue, recorded microscopic images for adipose tissue histology, and performed the IL-6 ELISAs and the adipose explant stimulated lipolysis assays. KG performed flow cytometric analysis of stromal adipose cells. GIS provided critical insight and reviewed the manuscript. KCC wrote the manuscript, performed statistical analyses, and created the figures. MJJ wrote the manuscript and designed and supervised the clamp experiments. EJW conceived of the study, wrote the manuscript, performed statistical analyses, and created figures.

\section{Acknowledgments}

This study was supported by NIH grants 1R01DK091276 (to EJW), DK076169 (to MJJ and EJW), DK099402 (to MJJ), and DK059635, DK40936, and DK45735 (to GIS). We also gratefully acknowledge the support of the James Peter Read Foundation, the UCSF Cardiovascular Research Institute, the UCSF Diabetes Center (P30 DK063720), and the UCSF Liver Center (P30 DK026743). We would like to thank Kay-Uwe Wagner from the University of Nebraska for providing the Jak2 conditional mice. We would also like to thank Ajay Chawla of UCSF for his advice and guidance.

Address correspondence to: Michael J. Jurczak, 200 Lothrop Street, E1144 BST, Pittsburgh, Pennsylvania 15213, USA. Phone: 412.648.7006; E-mail: jurczakm@pitt.edu. Or to: Ethan J. Weiss, 555 Mission Bay Boulevard South, 382Y, San Francisco, California 94158, USA. Phone: 415.514.0819; E-mail: Ethan.Weiss@ucsf.edu.

1. Houssay BA, Biasotti A. The hypophysis, carbohydrate metabolism and diabetes. Endocrinology. 1931;15(6):511-523.

2. Houssay BA. The hypophysis and metabolism. N Engl J Med. 1936;214(20):961-971.

3. Houssay BA. Carbohydrate metabolism. N Engl J Med. 1936;214(20):971-986.

4. Cushing H. Further Concerning a Parasympathetic Center in the Interbrain: VII. The Effect of Intraventricularly-Injected Histamine. Proc Natl Acad Sci U S A. 1932;18(7):500-510. 
5. Chabanier H, Copeman WS. A new system of treatment of diabetes mellitus. Br Med J. 1926;1(3412):897-898.

6. Luft R, Olivercrona H. Experiences with hypophysectomy in man. J Neurosurg. 1953;10(3):301-316.

7. Luft R, Olivercrona H, Ikkos D, Kornerup T, Ljunggren H. Hypophysectomy in man; further experiences in severe diabetes mellitus. Br Med J. 1955;2(4942):752-756.

8. Javid M, Gordon ES, Erickson TC. Hypophysectomy in severe diabetes. I. Neurosurgical aspects. J Neurosurg. 1958;15(5):504-511.

9. Greenberg E. GROWTH HORMONE AND DIABETES MELLITUS. Diabetes. 1965;14:43-45.

10. Guevara-Aguirre J, et al. Growth hormone receptor deficiency is associated with a major reduction in pro-aging signaling, cancer, and diabetes in humans. Sci Transl Med. 2011;3(70):70ra13.

11. List EO, et al. Endocrine parameters and phenotypes of the growth hormone receptor gene disrupted (GHR-/-) mouse. Endocr Rev. 2011;32(3):356-386.

12. Capatina C, Wass JA. 60 YEARS OF NEUROENDOCRINOLOGY: Acromegaly. J Endocrinol. 2015;226(2):T141-T160.

13. Valera A, Rodriguez-Gil JE, Yun JS, McGrane MM, Hanson RW, Bosch F. Glucose metabolism in transgenic mice containing a chimeric P-enolpyruvate carboxykinase/bovine growth hormone gene. FASEB J. 1993;7(9):791-800.

14. Steger RW, Bartke A, Cecim M. Premature ageing in transgenic mice expressing different growth hormone genes. J Reprod Fertil Suppl. 1993;46:61-75.

15. Chaves VE, Júnior FM, Bertolini GL. The metabolic effects of growth hormone in adipose tissue. Endocrine. 2013;44(2):293-302

16. Møller N, Jørgensen JO. Effects of growth hormone on glucose, lipid, and protein metabolism in human subjects. Endocr Rev. 2009;30(2):152-177.

17. Perry RJ, et al. Hepatic acetyl CoA links adipose tissue inflammation to hepatic insulin resistance and type 2 diabetes. Cell. 2015;160(4):745-758.

18. Perry RJ, et al. Leptin reverses diabetes by suppression of the hypothalamic-pituitary-adrenal axis. Nat Med. 2014;20(7):759-763.

19. Segerlantz M, Bramnert M, Manhem P, Laurila E, Groop LC. Inhibition of the rise in FFA by Acipimox partially prevents GHinduced insulin resistance in GH-deficient adults. J Clin Endocrinol Metab. 2001;86(12):5813-5818.

20. Nielsen S, Møller N, Christiansen JS, Jørgensen JO. Pharmacological antilipolysis restores insulin sensitivity during growth hormone exposure. Diabetes. 2001;50(10):2301-2308.

21. Fan Y, et al. Liver-specific deletion of the growth hormone receptor reveals essential role of growth hormone signaling in hepatic lipid metabolism. J Biol Chem. 2009;284(30):19937-19944.

22. Barclay JL, et al. GH-dependent STAT5 signaling plays an important role in hepatic lipid metabolism. Endocrinology. 2011;152(1):181-192.

23. Sos BC, et al. Abrogation of growth hormone secretion rescues fatty liver in mice with hepatocyte-specific deletion of JAK2. J Clin Invest. 2011;121(4):1412-1423.

24. Bartke A, Westbrook R. Metabolic characteristics of long-lived mice. Front Genet. 2012;3:288.

25. Mavalli MD, et al. Distinct growth hormone receptor signaling modes regulate skeletal muscle development and insulin sensitivity in mice. J Clin Invest. 2010;120(11):4007-4020.

26. Vijayakumar A, et al. Targeted loss of GHR signaling in mouse skeletal muscle protects against high-fat diet-induced metabolic deterioration. Diabetes. 2012;61(1):94-103.

27. Wu Y, et al. Growth hormone receptor regulates $\beta$ cell hyperplasia and glucose-stimulated insulin secretion in obese mice. $J$ Clin Invest. 2011;121(6):2422-2426.

28. List EO, et al. The role of GH in adipose tissue: lessons from adipose-specific GH receptor gene-disrupted mice. Mol Endocrinol. 2013;27(3):524-535

29. Mullican SE, Tomaru T, Gaddis CA, Peed LC, Sundaram A, Lazar MA. A novel adipose-specific gene deletion model demonstrates potential pitfalls of existing methods. Mol Endocrinol. 2013;27(1):127-134.

30. Nordstrom SM, Tran JL, Sos BC, Wagner KU, Weiss EJ. Disruption of JAK2 in adipocytes impairs lipolysis and improves fatty liver in mice with elevated GH. Mol Endocrinol. 2013;27(8):1333-1342.

31. Eguchi J, et al. Transcriptional control of adipose lipid handling by IRF4. Cell Metab. 2011;13(3):249-259

32. Titchenell PM, et al. Direct hepatocyte insulin signaling is required for lipogenesis but is dispensable for the suppression of glucose production. Cell Metab. 2016;23(6):1154-1166.

33. Finegood DT, Bergman RN, Vranic M. Estimation of endogenous glucose production during hyperinsulinemic-euglycemic glucose clamps. Comparison of unlabeled and labeled exogenous glucose infusates. Diabetes. 1987;36(8):914-924.

34. del Rincon JP, et al. Growth hormone regulation of p85alpha expression and phosphoinositide 3-kinase activity in adipose tissue: mechanism for growth hormone-mediated insulin resistance. Diabetes. 2007;56(6):1638-1646.

35. Gao Y, et al. The role of PTEN in chronic growth hormone-induced hepatic insulin resistance. PLoS One. 2013;8(6):e68105.

36. Davidson MB. Effect of growth hormone on carbohydrate and lipid metabolism. Endocr Rev. 1987;8(2):115-131.

37. Press M, Tamborlane WV, Sherwin RS. Importance of raised growth hormone levels in mediating the metabolic derangements of diabetes. NEngl J Med. 1984;310(13):810-815.

38. McMenamin SK, Minchin JE, Gordon TN, Rawls JF, Parichy DM. Dwarfism and increased adiposity in the gh1 mutant zebrafish vizzini. Endocrinology. 2013;154(4):1476-1487.

39. Shi SY, et al. Adipocyte-specific deficiency of Janus kinase (JAK) 2 in mice impairs lipolysis and increases body weight, and leads to insulin resistance with ageing. Diabetologia. 2014;57(5):1016-1026.

40. Lee KY, et al. Lessons on conditional gene targeting in mouse adipose tissue. Diabetes. 2013;62(3):864-874.

41. Martens JH, Stunnenberg HG. The molecular signature of oncofusion proteins in acute myeloid leukemia. FEBS Lett. 2010;584(12):2662-2669.

42. Petersen MC, et al. Insulin receptor Thr1160 phosphorylation mediates lipid-induced hepatic insulin resistance. J Clin Invest. 2016;126(11):4361-4371.

43. Cantley JL, et al. CGI-58 knockdown sequesters diacylglycerols in lipid droplets/ER-preventing diacylglycerol-mediated hepatic insulin resistance. Proc Natl Acad Sci USA. 2013;110(5):1869-1874

44. Wilson CG, Tran JL, Erion DM, Vera NB, Febbraio M, Weiss EJ. Hepatocyte-specific disruption of CD36 attenuates fatty liver and improves insulin sensitivity in HFD-fed mice. Endocrinology. 2016;157(2):570-585. 
45. Nur BG, Gencpinar P, Yuzbasioglu A, Emre SD, Mihci E. Chanarin-Dorfman syndrome: Genotype-Phenotype Correlation. Eur J Med Genet. 2015;58(4):238-242

46. Lallukka S, Yki-Järvinen H. Non-alcoholic fatty liver disease and risk of type 2 diabetes. Best Pract Res Clin Endocrinol Metab. 2016;30(3):385-395.

47. Pal A, et al. PTEN mutations as a cause of constitutive insulin sensitivity and obesity. N Engl J Med. 2012;367(11):1002-1011.

48. Guevara-Aguirre J, et al. GH receptor deficiency in Ecuadorian adults is associated with obesity and enhanced insulin sensitivity. J Clin Endocrinol Metab. 2015;100(7):2589-2596.

49. Carey DG, et al. Effect of rosiglitazone on insulin sensitivity and body composition in type 2 diabetic patients [corrected]. Obes Res. 2002;10(10):1008-1015.

50. Taniguchi CM, Emanuelli B, Kahn CR. Critical nodes in signalling pathways: insights into insulin action. Nat Rev Mol Cell Biol. 2006;7(2):85-96.

51. Choi YH, et al. Alterations in regulation of energy homeostasis in cyclic nucleotide phosphodiesterase 3B-null mice. J Clin Invest. 2006;116(12):3240-3251.

52. Choi SM, et al. Insulin regulates adipocyte lipolysis via an Akt-independent signaling pathway. Mol Cell Biol. 2010;30(21):5009-5020

53. Randle PJ, Garland PB, Hales CN, Newsholme EA. The glucose fatty-acid cycle. Its role in insulin sensitivity and the metabolic disturbances of diabetes mellitus. Lancet. 1963;1(7285):785-789.

54. Boden G. Gluconeogenesis and glycogenolysis in health and diabetes. J Investig Med. 2004;52(6):375-378.

55. Daniele G, et al. Chronic reduction of plasma free fatty acid improves mitochondrial function and whole-body insulin sensitivity in obese and type 2 diabetic individuals. Diabetes. 2014;63(8):2812-2820.

56. Hadigan C, Liebau J, Torriani M, Andersen R, Grinspoon S. Improved triglycerides and insulin sensitivity with 3 months of acipimox in human immunodeficiency virus-infected patients with hypertriglyceridemia. J Clin Endocrinol Metab. 2006;91(11):4438-4444.

57. Fulcher GR, et al. A double blind study of the effect of acipimox on serum lipids, blood glucose control and insulin action in non-obese patients with type 2 diabetes mellitus. Diabet Med. 1992;9(10):908-914.

58. Fulcher GR, Walker M, Catalano C, Agius L, Alberti KG. Metabolic effects of suppression of nonesterified fatty acid levels with acipimox in obese NIDDM subjects. Diabetes. 1992;41(11):1400-1408.

59. Hochberg I, Tran QT, Barkan AL, Saltiel AR, Chandler WF, Bridges D. Gene Expression Signature in Adipose Tissue of Acromegaly Patients. PLoS ONE. 2015;10(6):e0129359.

60. Thankamony A, et al. Short-term administration of pegvisomant improves hepatic insulin sensitivity and reduces soleus muscle intramyocellular lipid content in young adults with type 1 diabetes. J Clin Endocrinol Metab. 2014;99(2):639-647.

61. Bergan HE, Kittilson JD, Sheridan MA. Nutritional state modulates growth hormone-stimulated lipolysis. Gen Comp Endocrinol. 2015;217-218:1-9

62. O-Sullivan I, et al. FoxO1 integrates direct and indirect effects of insulin on hepatic glucose production and glucose utilization. Nat Commun. 2015;6:7079.

63. Lewis GF, Zinman B, Groenewoud Y, Vranic M, Giacca A. Hepatic glucose production is regulated both by direct hepatic and extrahepatic effects of insulin in humans. Diabetes. 1996;45(4):454-462.

64. Girard J. The Inhibitory Effects of Insulin on Hepatic Glucose Production Are Both Direct and Indirect. Diabetes. 2006;55(Supplement 2):S65-SS9.

65. Lewis GF, Vranic M, Harley P, Giacca A. Fatty acids mediate the acute extrahepatic effects of insulin on hepatic glucose production in humans. Diabetes. 1997;46(7):1111-1119.

66. Levine R, Fritz IB. The relation of insulin to liver metabolism. Diabetes. 1956;5(3):209-19; discussion, 219.

67. Morley TS, Xia JY, Scherer PE. Selective enhancement of insulin sensitivity in the mature adipocyte is sufficient for systemic metabolic improvements. Nat Commun. 2015;6:7906.

68. Klebanov S, Astle CM, DeSimone O, Ablamunits V, Harrison DE. Adipose tissue transplantation protects ob/ob mice from obesity, normalizes insulin sensitivity and restores fertility. J Endocrinol. 2005;186(1):203-211.

69. Gavrilova O, et al. Surgical implantation of adipose tissue reverses diabetes in lipoatrophic mice. J Clin Invest. 2000;105(3):271-278

70. Foster MT, Softic S, Caldwell J, Kohli R, de Kloet AD, Seeley RJ. Subcutaneous adipose tissue transplantation in diet-induced obese mice attenuates metabolic dysregulation while removal exacerbates it. Physiol Rep. 2013;1(2):2.

71. Bindlish S, Presswala LS, Schwartz F. Lipodystrophy: Syndrome of severe insulin resistance. Postgrad Med. 2015;127(5):511-516.

72. Takano A, et al. Growth hormone induces cellular insulin resistance by uncoupling phosphatidylinositol 3-kinase and its downstream signals in 3T3-L1 adipocytes. Diabetes. 2001;50(8):1891-1900.

73. Krempler A, Qi Y, Triplett AA, Zhu J, Rui H, Wagner KU. Generation of a conditional knockout allele for the Janus kinase 2 (Jak2) gene in mice. Genesis. 2004;40(1):52-57.

74. Jurczak MJ, et al. Dissociation of inositol-requiring enzyme (IRE1 $\alpha$ )-mediated c-Jun N-terminal kinase activation from hepatic insulin resistance in conditional X-box-binding protein-1 (XBP1) knock-out mice. J Biol Chem. 2012;287(4):2558-2567.

75. Ayala JE, et al. Standard operating procedures for describing and performing metabolic tests of glucose homeostasis in mice. Dis Model Mech. 2010;3(9-10):525-534. 